\title{
MEdição dA EMISSÃo de AldEÍdos E ÁlCOOL Não QUEIMAdO EM MOTOCIClETAS OPERANDO NOS CicLOS WMTC E ECE R40
}

\author{
Alfred Szwarc ${ }^{1}$, Gabriel Murgel Branco ${ }^{1}$, Janaine Aparecida da $\mathrm{Cruz}^{2}$, Renato Romio ${ }^{3}$, \\ Rodrigo Faggi ${ }^{3}$, \\ ${ }^{1}$ AFEEVAS - Associação dos Fabricantes de Equipamentos para Controle de Emissões \\ Veiculares da América do Sul \\ ${ }^{2}$ Umicore Brasil Ltda. \\ ${ }^{3}$ Instituto Mauá de Tecnologia
}

E-mails: alfreds@terra.com.br, gabriel.tcl@uol.com.br, janaine.carvalho@am.umicore.com, romio@maua.br, faggi@maua.br,

\section{RESUMO}

O advento dos motociclos bi-combustível suscita a preocupação com a emissão de aldeídos e etanol não queimado nestes veículos. Complementarmente, a fase 4 do PROMOT adotou o ciclo WMTC - World Motorcycle Test Cycle, em substituição ao ciclo ECE R40, a partir de $1^{\circ}$ de janeiro do ano de 2014 , tornando o ensaio de emissões mais representativo das condições reais de utilização.

Este trabalho caracteriza as emissões de "ÁLCOOL NÃO QUEIMADO - ANQ" e "ALDEÍDOS" em uma motocicleta comum e apresenta os resultados obtidos num estudo comparativo das emissões, inclusive os resultados dos principais poluentes $\left(\mathrm{CO}, \mathrm{HC}, \mathrm{NO}_{\mathrm{X}}\right.$, e $\mathrm{CO}_{2}$ ) e do consumo de combustível, medidos nos dois ciclos, como subsídio para novas estratégias para o PROMOT e para o aprimoramento dos inventários de emissões.

Estes resultados mostram que existem diferenças significativas no nível de emissões de poluentes entre os dois ciclos e também demonstram que os valores de aldeídos e álcool não queimado em motociclos, são superiores aos observados nos automóveis, mostrando que são itens importantes para controle ambiental e a evolução tecnológica destes veículos no Brasil.

A partir deste estudo também é possível extrair informações úteis e relevantes à definição de estratégias de calibração dos motores de combustão interna utilizados em motociclos, bem como auxiliar nas estratégias para desenvolvimento de dispositivos de pós-tratamento de gases provenientes da combustão.

\section{INTRODUÇÃO}

O inventário de fontes móveis de emissões atmosféricas ${ }^{[1]}$ indica que os veículos a etanol e a gasolina ainda são os maiores responsáveis pela emissão de compostos orgânicos, com participação expressiva dos motociclos no potencial de formação de ozônio. O CONAMA vêm intensificando as exigências para o controle de emissões, sendo que em sua resolução 
$\mathrm{n}^{\mathrm{o}} 432$ de 13 de julho de 2011 define novos procedimentos de ensaio e limites para motociclos e similares, cujos valores são mostrados na tabela 1 a seguir.

Tabela 1 - Limites de emissão para motociclos (exceto ciclomotores)

\begin{tabular}{|c|c|c|c|c|c|c|c|c|}
\hline \multirow[b]{2}{*}{ Categoria } & \multirow[b]{2}{*}{$\begin{array}{l}\text { Data de } \\
\text { Vigência }\end{array}$} & \multirow[b]{2}{*}{$\begin{array}{l}\text { Velocidade } \\
\text { Máxima }\end{array}$} & \multicolumn{6}{|c|}{ Limites } \\
\hline & & & $\begin{array}{c}\mathrm{CO} \\
(\mathrm{g} / \mathrm{km})\end{array}$ & $\begin{array}{c}\mathrm{HC} \\
(\mathrm{g} / \mathrm{km})\end{array}$ & $\begin{array}{c}\mathrm{NO}_{\mathrm{X}} \\
(\mathrm{g} / \mathrm{km})\end{array}$ & $\mathrm{CO}_{2}$ & $\begin{array}{c}\text { Evap. } \\
\text { (g/teste) }\end{array}$ & $\begin{array}{c}\text { Durab. } \\
(\mathrm{km})\end{array}$ \\
\hline \multirow{4}{*}{$\begin{array}{l}\text { Motociclos } \\
\text { e Similares }\end{array}$} & \multirow{2}{*}{$01 / 01 / 2014$} & & 2,0 & 0,80 & 0,15 & - & - & 18.000 \\
\hline & & $\geq 1$ & 2,0 & 0,30 & 0,15 & - & - & 00 \\
\hline & \multirow{2}{*}{$01 / 01 / 2016$} & $<13$ & 2,0 & 0,56 & 0,13 & \multirow{2}{*}{ Informar } & \multirow{2}{*}{$\begin{array}{l}1,0 \text { fase } \\
\text { quente }\end{array}$} & 18.000 \\
\hline & & $\geq 130 \mathrm{~km} / \mathrm{h}$ & 2,0 & 0,25 & 0,17 & & & 30.000 \\
\hline
\end{tabular}

Nota: A emissão de CO e HC em marcha lenta deve ser medida e divulgada, assim como a emissão de $\mathrm{CO}_{2}$ medida no ciclo de condução.

Esta mesma resolução estabelece os procedimentos de ensaios para a determinação dos gases de escapamento previstos na regulamentação da Comunidade Europeia (ECE/TRANS/180/Add.2), utilizando-se o ciclo de condução transiente WMTC "Worldwide Motorcycle Test Cycle". São preconizadas três fases distintas para o ciclo, de forma que a terceira é utilizada apenas para motociclos que possuem velocidade superior a $130 \mathrm{~km} / \mathrm{h}$, condição não atingida para a maioria dos motociclos da frota brasileira. Por isso esta condição foi considerada fora do escopo deste trabalho. A figura 1 mostra graficamente o ciclo WMTC distinguindo as três fases.

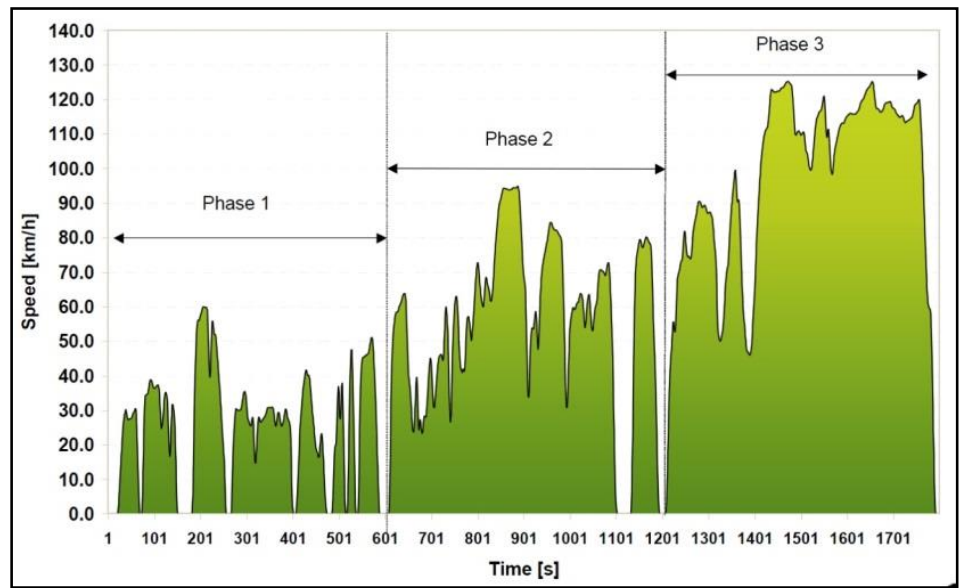

Figura 1 - Ciclo WMTC

Conforme já exposto, este ciclo substitui o ciclo ECE R40, cujo perfil de velocidade em função do tempo é mostrado na figura 2 ao lado. A segunda parte do ciclo representa o ciclo extra urbano.

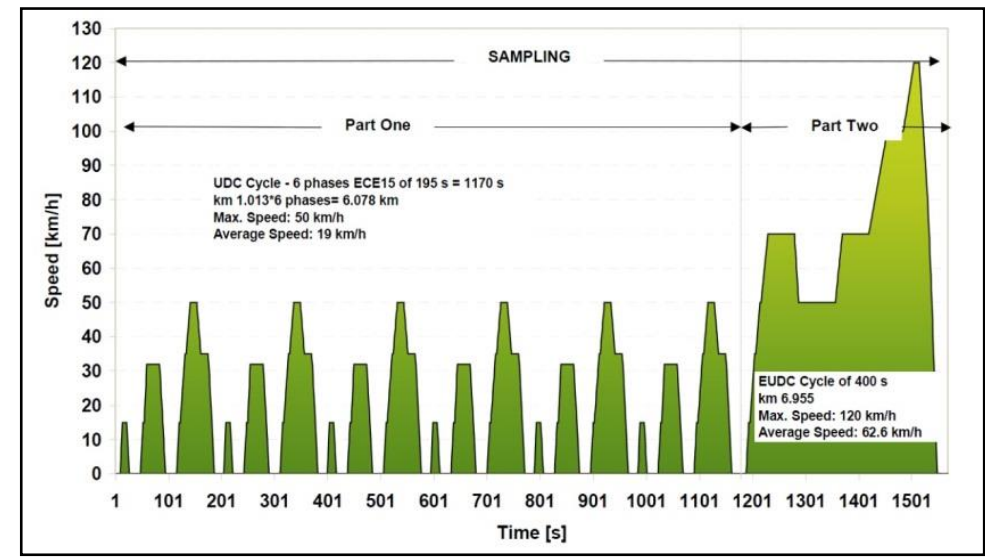

Figura 2 - Ciclo ECE R40

Estas regulamentações para o controle de emissões vêm se transformando para conferir maior representatividade dos procedimentos de ensaio, tanto em relação ao comportamento dos motociclos em uso normal, quanto em relação aos seus impactos ambientais. O propósito deste estudo é oferecer uma comparação dos resultados obtidos com os dois ciclos de 
condução, especialmente no que concerne à emissão de compostos orgânicos hidrocarbonetos (HC), álcool não queimado (ANQ) e aldeídos (CHO) - regulamentada apenas para $\mathrm{HC}$ e cujo efeito sobre o meio ambiente é significativo sob o ponto de vista da formação de ozônio. Neste aspecto, ressalta-se que a emissão evaporativa não foi objeto deste trabalho, mas deve ser melhor caracterizada, como vem sendo realizado nos veículos leves do ciclo Otto ${ }^{[2]}$.

\section{INFORMAÇÕES GERAIS}

\subsection{Considerações}

Os ensaios foram realizados no Laboratório de Emissões do Instituto Mauá de Tecnologia, o qual participa do programa de correlação da AEA - Associação Brasileira de Engenharia Automotiva.

Os combustíveis utilizados foram gasolina com $22 \%$ de álcool anidro, e álcool hidratado com $5,5 \%$ de água destilada ${ }^{[3]}$.

As amostras de aldeídos e álcool não queimado foram coletadas no Instituto Mauá de Tecnologia e analisadas pela Umicore Brasil Ltda. A análise de aldeídos foi realizada por método de cromatografia líquida ${ }^{[4]}$, e a análise de álcool não queimado foi realizada por método de cromatografia gasosa ${ }^{[5]}$.

Foram realizados seis ensaios para cada ciclo e por tipo de combustível. Para cálculo das médias e apresentação dos resultados foram considerados os resultados dos três últimos ensaios após a estabilização do motociclo.

Os resultados são também apresentados por fase, sendo a fase 1 definida como fase fria, e a fase 2 definida como fase quente.

\subsection{Seleção do Motociclo}

O veículo escolhido para a comparação é um motociclo Honda FAN $150\left(149,2 \mathrm{~cm}^{3}\right.$ de deslocamento) por ser considerado representativo de mais de $80 \%$ da frota circulante, especialmente a utilizada para a prestação de serviços de motofrete. Para os propósitos deste trabalho este veículo possui motor Flex.

O ciclo WMTC classifica o motociclo em termos de capacidade do motor e velocidade máxima do veículo, dividindo em classes e sub-classes, como mostrado na figura 3. O veículo escolhido se enquadra na classe 2 / sub-classe 2-1. Dessa forma, não há necessidade da utilização da parte 3 do ciclo de condução. 


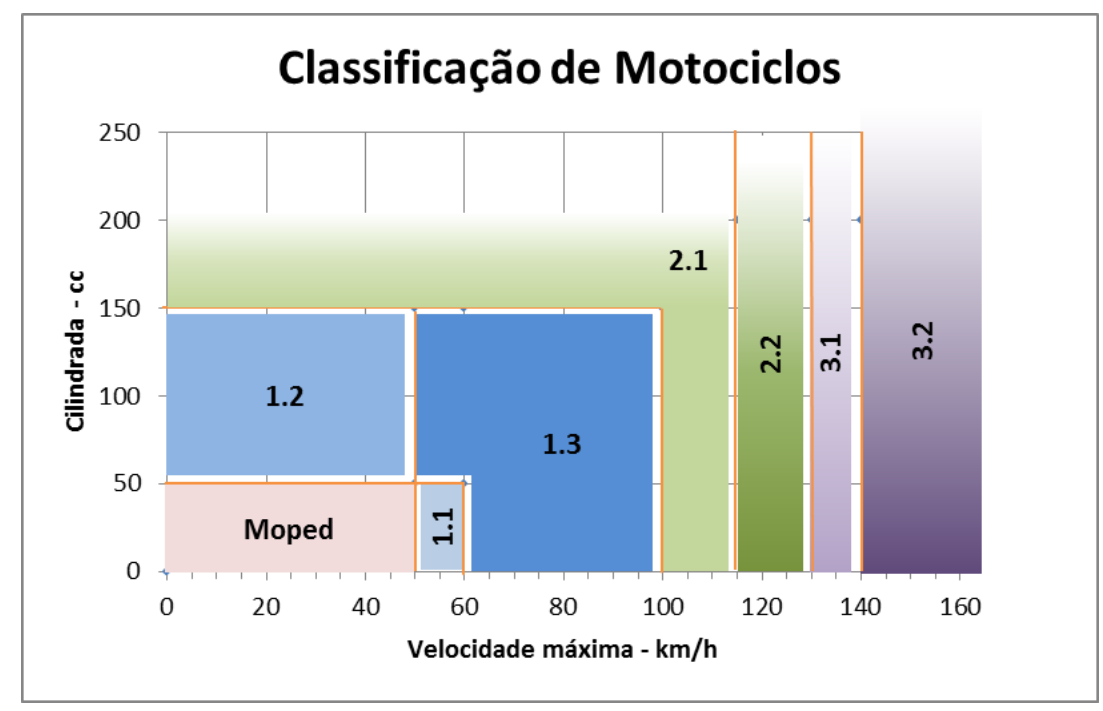

Figura 3 - Classes para o ensaio WMTC

1.3. Definição dos ciclos

Em função do motociclo utilizado, a regulamentação para o ciclo WMTC especifica a utilização de apenas as partes 1 e 2 da seguinte forma:

- $\quad$ Parte 1 (fase fria) - com velocidade reduzida;

- Parte 2 (fase quente) - com velocidade reduzida;

- $\quad$ Parte 3 (continuação da fase quente) - não se aplica.

Dessa forma, a figura 4 mostra as partes 1 e 2 do ciclo WMTC onde as linhas vermelhas representam as velocidades reduzidas executadas nos ensaios.
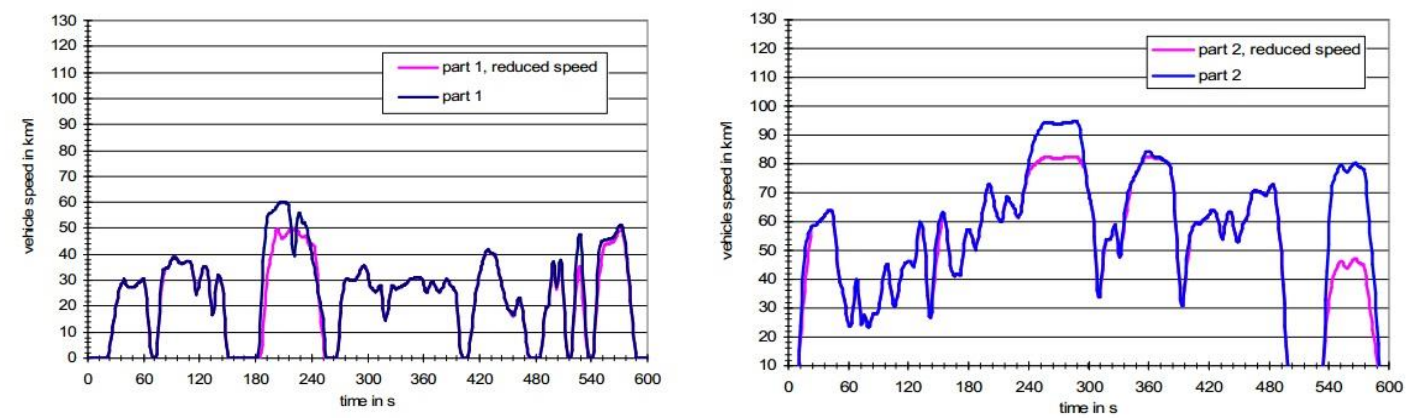

Figura 4 - Ciclo WMTC para motociclos de $150 \mathrm{~cm}^{3}$

Para o ciclo ECE R40 foi utilizado apenas o ciclo urbano, onde a velocidade máxima atingida é de $50 \mathrm{~km} / \mathrm{h}$, sem o trecho extra urbano, também dispensado neste tipo de motociclo. Foram realizados 6 ciclos urbanos em cada ensaio (cada um com 195 segundos e velocidade máxima de $50 \mathrm{~km} / \mathrm{h}$ ), sendo os 2 primeiros considerados como fase fria e 4 últimos como fase quente. A coleta dos gases das respectivas fases foi realizada em balões distintos. 


\section{RESULTADOS}

Os resultados dos ensaios para todas as emissões e o consumo de combustível estão apresentados no Anexo deste trabalho. De uma forma geral, todos os ensaios se mostraram repetitivos, permitindo comparações válidas para cada caso.

Quando o motor funciona com gasolina (E22), a emissão de compostos orgânicos se concentra em HC e aldeídos, cujos resultados são bastante elevados nas fases frias, em ambos os ciclos de teste. A emissão de HC é mais elevada no ciclo antigo, enquanto que a de aldeídos é 5 vezes maior no ciclo WMTC.

Os gráficos da figura 5 permitem as diversas comparações possíveis entre os resultados obtidos em cada ensaio realizado com gasolina.

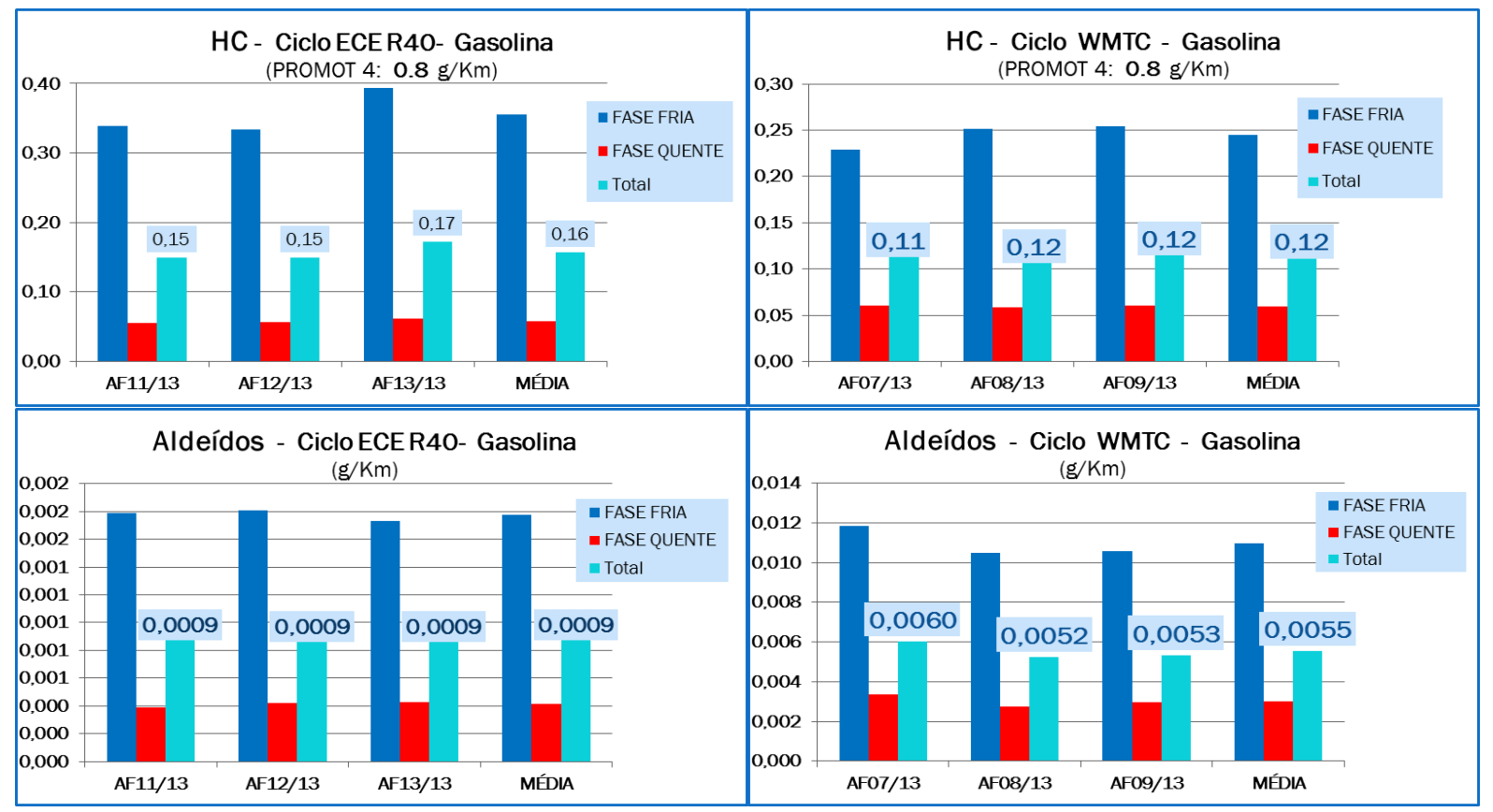

Figura 5 - Emissões de hidrocarbonetos e aldeídos, funcionando com gasolina

Quando o motor funciona com álcool hidratado, os compostos orgânicos emitidos também incluem uma quantidade significativa de etanol. Novamente, os resultados são bastante elevados nas fases frias, em ambos os ciclos de teste.

Considerando que a representatividade do tráfego normal é maior no ciclo WMTC, os resultados obtidos neste ciclo devem ser tomados como mais realistas para a simulação do uso cotidiano e melhores para a comparação com outros tipos de veículo.

Por outro lado, os resultados obtidos no ciclo europeu antigo, sem o trecho extra urbano, fornecem uma visão do que ocorre em regimes mais brandos de utilização e em trechos mais curtos.

Os gráficos da figura 6 permitem as diversas comparações possíveis entre os resultados obtidos em cada ensaio realizado com etanol. 


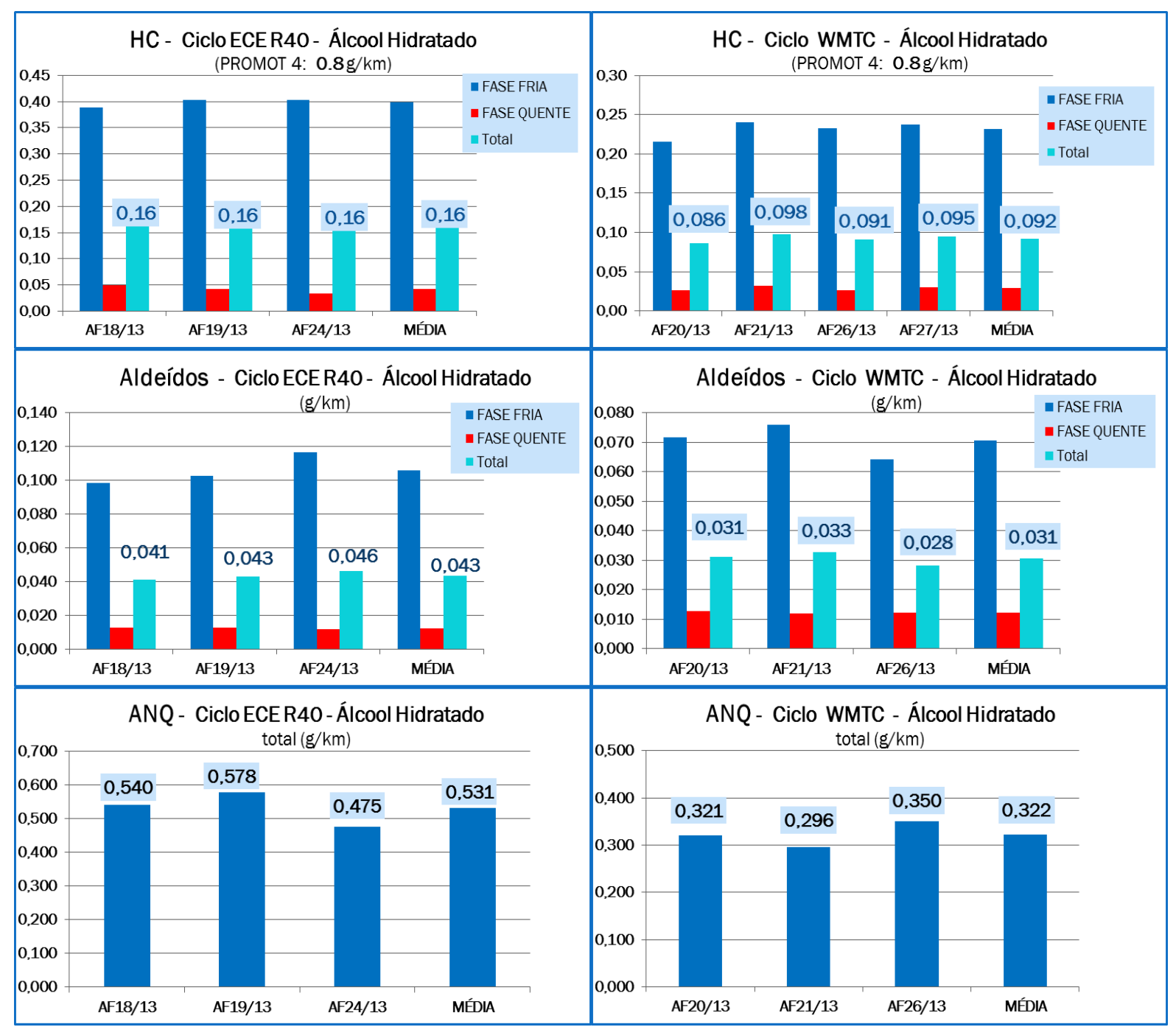

Figura 6 - Emissões de hidrocarbonetos, aldeídos e ANQ, funcionando com álcool hidratado

A comparação das médias finais permite observar que o ensaio WMTC é mais severo para as emissões de compostos orgânicos com o motor funcionando com os dois combustíveis, exceto para aldeídos quando funcionando com gasolina, sendo que a emissão de álcool não queimado é praticamente nula nas fases quentes dos dois ciclos de condução.

Adicionalmente, as respectivas emissões de $\mathrm{HC}$, aldeídos e álcool não queimado características dos automóveis e veículos leves (LDV) em geral foram colocadas nos próximos gráficos para comparação da ordem de grandeza dessas mesmas emissões medidas na motocicleta ensaiada. Para isso, foram consideradas as medianas das emissões de $\mathrm{HC}$ e aldeídos de 200 modelos de veículos certificados, cujos valores estão em conformidade com os limites L6 do PROCONVE, constantes do site da ANFAVEA ${ }^{[6]}$. Para a emissão de ANQ foi tomada a mediana de 443 modelos de veículos utilizados pela CETESB para o estudo da regulamentação desta emissão para os veículos leves.

Embora os ensaios realizados para este estudo sejam de um único veículo, esta comparação demonstra que a emissão de aldeídos e álcool não queimado pelos motociclos pode não ser desprezível, quando comparada às dos automóveis e sua regulamentação deve ser discutida. 


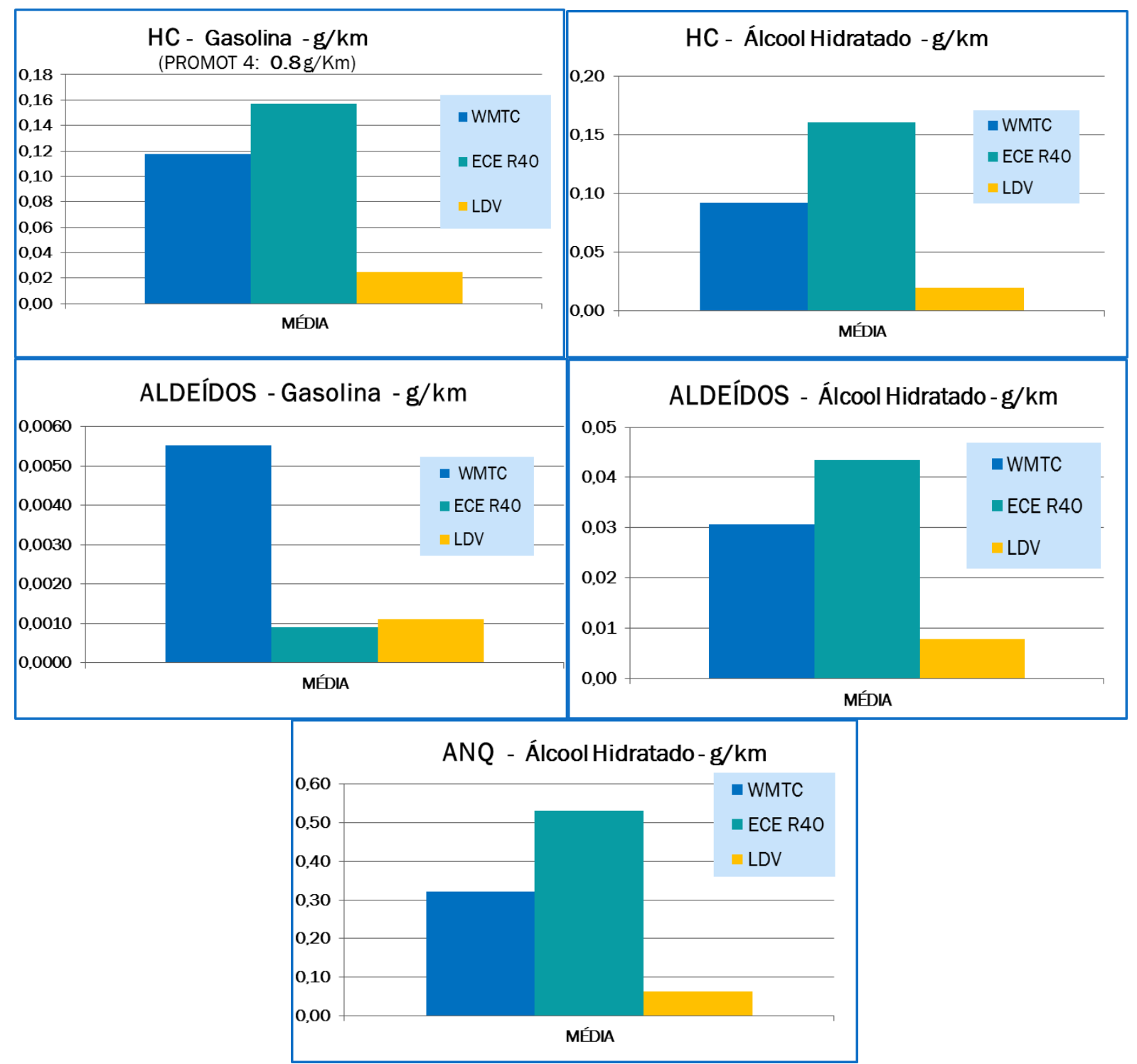

Figura 7 - Comparação das emissões médias de compostos orgânicos

\section{CONSIDERAÇÕES ADICIONAIS}

O conceito fundamental para a discussão da importância da regulamentação de aldeídos e álcool não queimado deve ser o mesmo que foi proposto para os veículos leves Flex, isto é, a comparação do potencial de formação de ozônio ${ }^{[7]}$.

O potencial de formação de ozônio é definido pela soma das emissões de cada composto orgânico ponderadas pelos respectivos MIR (máximo incremento de reatividade). Tomando por base os valores encontrados de HC, aldeídos, ANQ obtidos nos ensaios segundo o ciclo WMTC, bem como os valores de MIR propostos para os veículos leves, o potencial de ozônio do motociclo ensaiado é de $0,5 \mathrm{gO}_{3} / \mathrm{km}$ funcionando com gasolina e $0,7 \mathrm{gO}_{3} / \mathrm{km}$ funcionando com etanol, o que corresponde a uma emissão equivalente de $\mathrm{HC}$ de $0,13 \mathrm{~g} / \mathrm{km} \mathrm{e} 0,16 \mathrm{~g} / \mathrm{km}$, respectivamente. A tabela 2 apresenta os cálculos que suportam esta afirmação. 
Tabela 2 - Cálculo do potencial de ozônio para o motociclo ensaiado no ciclo WMTC

\begin{tabular}{|l|c|c|c|c|c|}
\hline & MIR & E22 & O3_gasolina & E100 & O3_etanol \\
\hline NMHC & 4,26 & 0,1174 & 0,500 & $\left.0 *^{*}\right)$ & 0,000 \\
\hline ANQ & 1,53 & 0,0000 & 0,000 & 0,322 & 0,493 \\
\hline CHO & 9,43 & 0,0028 & 0,027 & 0,004 & 0,036 \\
\hline CH3CHO & 6,54 & 0,0027 & 0,018 & 0,027 & 0,173 \\
\hline Total & & & 0,544 & & 0,703 \\
\hline HC_eq & & & 0,128 & & 0,165 \\
\hline
\end{tabular}

(*) Valor nulo em razão do desconto de $50 \%$ do ANQ (correção da medição por ionização de chama)

Estes resultados, indicam que o potencial de formação de ozônio das emissões orgânicas do motociclo ensaiado é 30\% maior quando se utiliza álcool hidratado, indicando a necessidade de aprimoramento do motor bi-combustível para corrigir esta distorção. Além disso, este potencial corresponde a três vezes mais $\mathrm{HC}$ do que o limite deste poluente para veículos leves e, por isso, deve ser buscada a sua redução.

Adicionalmente, é importante ressaltar que a emissão de $\mathrm{NO}_{\mathrm{X}}$, geralmente tomada como baixa para os motociclos, mostrou-se bastante elevada no ciclo WMTC (figura 8), o que reforça a necessidade do seu controle mais severo e de revisão dos inventários calculados com base nos valores levantados segundo o método ECE R40, já ultrapassado. Este fato se deve à carga imposta pelo ciclo WMTC, cujas velocidades atingem os $82,5 \mathrm{~km} / \mathrm{h}$ contra o máximo de 50 $\mathrm{km} / \mathrm{h}$ no ciclo ECE R40, para classe de motociclo testado.

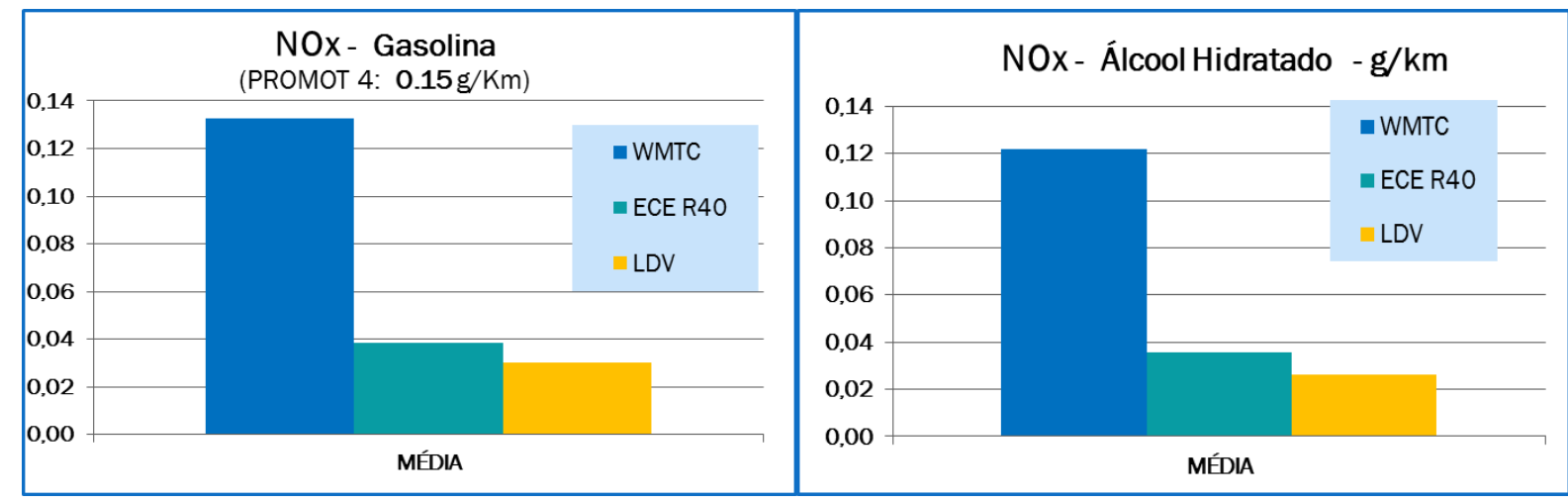

Figura 8 - Comparação das emissões médias de $\mathrm{NO}_{X}$ 


\section{CONCLUSÃO}

A emissão de aldeídos em motociclos em ambos os ciclos é mais elevada do que em automóveis de passeio em seu respectivo ciclo de teste, sendo melhor caracterizada no ciclo WMTC:

- $\quad 30 \mathrm{mg} / \mathrm{km}$ no ciclo WMTC e 43mg/km no ECE R40, utilizando álcool hidratado;

- $6 \mathrm{mg} / \mathrm{km}$ no ciclo WMTC e $1 \mathrm{mg} / \mathrm{km}$ no ECE R40, utilizando gasolina.

A emissão de álcool não queimado é significativa em ambos os ciclos quando se utiliza álcool hidratado como combustível, sendo 3,5 vezes superior à emissão de $\mathrm{HC}$, apresentando valor inferior no ciclo WMTC $(322 \mathrm{mg} / \mathrm{km})$ e maior no ciclo ECE R40 $(531 \mathrm{mg} / \mathrm{km})$.

O potencial de formação de ozônio das emissões orgânicas do motociclo bi-combustível é $30 \%$ maior quando utiliza álcool hidratado e 3 vezes maior do que o dos automóveis, indicando a necessidade de aprimoramento dos motociclos.

Visando uma abordagem mais precisa do controle ambiental, recomenda-se que a emissão de compostos orgânicos, inclusive a evaporativa, dos motociclos seja expressa em função do potencial de ozônio, como está sendo revisto para os automóveis de passeio.

No ciclo WMTC com velocidades mais realistas do que no ciclo ECE R40, a emissão de $\mathrm{NO}_{\mathrm{X}}$ também se eleva, atingindo valores próximos do limite máximo legislado pelo PROMOT 4. Neste caso, as exigências para motociclos também são mais tolerantes do que para os automóveis e devem ser intensificadas.

O nível de emissão de CO, no ciclo WMTC, é superior utilizando álcool hidratado em relação à gasolina, os níveis de $\mathrm{HC}$ e $\mathrm{NO}_{\mathrm{X}}$ são ligeiramente inferiores neste caso. Com exceção do $\mathrm{NO}_{\mathrm{X}}$, os demais resultados apresentaram valores razoavelmente inferiores aos limites legislados pelo PROMOT 4.

\section{REFERÊNCIAS}

[1] Branco, G.M.; Branco, F.C.; Xavier, M. - Ampliação do inventário de emissões veiculares para a gestão dos transportes no estado de São Paulo - SIMEA 2013.

[2] Szwarc, A.; Farah, E.L.; Branco, G.M.; Branco, F.C. - Redução da emissão evaporativa do veículo em movimento e no reabastecimento de combustível - SIMEA 2014.

[3] ABNT NBR 8689: Veículos Automotores Leves - Combustíveis para Ensaio - Requisitos, 2012.

[4] ABNT NBR 12026: Veículos rodoviários automotores leves - Determinação de aldeídos e cetonas contidos no gás de escapamento, por cromatografia líquida - Método DNPH, 2009.

[5] ABNT NBR: 15598: Veículos rodoviários automotores leves - Determinação de etanol não queimado contido no gás de escapamento, por cromatografia gasosa - Método de ensaio, 2008.

[6] http://www.anfavea.com.br/tecnica.html. Acesso em 20/05/2014

[7] Branco, G.M.; Szwarc, A.; Branco, F.C; Nigro, F.E.B. - Controle de emissão de compostos orgânicos com base no potencial de formação de ozônio - SIMEA 2013. 


\section{ANEXO - Tabelas de resultados dos ensaios}

A) Combustível álcool hidratado

Combustível Etanol - ECE R40

\begin{tabular}{|c|c|c|c|c|c|c|c|c|c|c|c|c|}
\hline \multirow{2}{*}{ TESTES } & \multicolumn{3}{|c|}{ CO $(\mathrm{g} / \mathrm{km})$} & \multicolumn{3}{c|}{ HC $(\mathrm{g} / \mathrm{km})$} & \multicolumn{3}{c|}{ NO $(\mathrm{g} / \mathrm{km})$} & \multicolumn{3}{c|}{ C02 $(\mathrm{g} / \mathrm{km})$} \\
\cline { 2 - 14 } & $\begin{array}{c}\text { Fase } \\
\text { fria }\end{array}$ & $\begin{array}{c}\text { Fase } \\
\text { quente }\end{array}$ & Total & $\begin{array}{c}\text { Fase } \\
\text { fria }\end{array}$ & $\begin{array}{c}\text { Fase } \\
\text { quente }\end{array}$ & Total & $\begin{array}{c}\text { Fase } \\
\text { fria }\end{array}$ & $\begin{array}{c}\text { Fase } \\
\text { quente }\end{array}$ & Total & $\begin{array}{c}\text { Fase } \\
\text { fria }\end{array}$ & $\begin{array}{c}\text { Fase } \\
\text { quente }\end{array}$ & Total \\
\hline AF18/13 & 3,79 & 0,22 & 1,41 & 0,389 & 0,049 & 0,163 & 0,041 & 0,036 & 0,038 & 50,5 & 47,0 & 48,2 \\
\hline AF19/13 & 3,80 & 0,22 & 1,42 & 0,403 & 0,043 & 0,164 & 0,035 & 0,037 & 0,036 & 50,7 & 48,4 & 49,2 \\
\hline AF24/13 & 3,89 & 0,16 & 1,39 & 0,403 & 0,034 & 0,156 & 0,036 & 0,032 & 0,033 & 50,4 & 46,4 & 47,7 \\
\hline MÉDIA & 3,83 & 0,20 & 1,41 & 0,399 & 0,042 & 0,161 & 0,037 & 0,035 & 0,036 & 50,5 & 47,3 & 48,4 \\
\hline
\end{tabular}

\begin{tabular}{|c|c|c|c|c|c|c|c|c|c|c|c|c|}
\hline \multirow{2}{*}{ TESTES } & \multicolumn{3}{|c|}{ Formaldeido $(\mathrm{g} / \mathrm{km})$} & \multicolumn{3}{|c|}{ Acetaldeído $(\mathrm{g} / \mathrm{km})$} & \multicolumn{3}{c|}{ Aldeídos Totais $\mathbf{( g / k m )}$} & \multicolumn{3}{c|}{ ANQ (g/km) } \\
\cline { 2 - 14 } & $\begin{array}{c}\text { Fase } \\
\text { fria }\end{array}$ & $\begin{array}{c}\text { Fase } \\
\text { quente }\end{array}$ & Total & $\begin{array}{c}\text { Fase } \\
\text { fria }\end{array}$ & $\begin{array}{c}\text { Fase } \\
\text { quente }\end{array}$ & Total & $\begin{array}{c}\text { Fase } \\
\text { fria }\end{array}$ & $\begin{array}{c}\text { Fase } \\
\text { quente }\end{array}$ & Total & $\begin{array}{c}\text { Fase } \\
\text { fria }\end{array}$ & $\begin{array}{c}\text { Fase } \\
\text { quente }\end{array}$ & Total \\
\hline AF18/13 & 0,010 & 0,005 & 0,007 & 0,088 & 0,008 & 0,035 & 0,0985 & 0,0124 & 0,0412 & 1,615 & 0,000 & 0,540 \\
\hline AF19/13 & 0,010 & 0,005 & 0,007 & 0,093 & 0,008 & 0,036 & 0,1027 & 0,0128 & 0,0429 & 1,723 & 0,000 & 0,578 \\
\hline AF24/13 & 0,012 & 0,004 & 0,007 & 0,104 & 0,008 & 0,040 & 0,1165 & 0,0115 & 0,0463 & 1,434 & 0,000 & 0,475 \\
\hline MÉDIA & 0,011 & 0,005 & 0,007 & 0,095 & 0,008 & 0,037 & 0,1059 & 0,0122 & 0,0435 & 1,591 & 0,000 & 0,531 \\
\hline
\end{tabular}

\begin{tabular}{|c|c|c|c|c|c|c|c|c|c|}
\hline \multirow{2}{*}{ TESTES } & \multicolumn{3}{|c|}{ Consumo (I/100km) } & \multicolumn{3}{c|}{ Autonomia (km/l) } & \multicolumn{3}{c|}{ Distância pecorrida $(\mathrm{km})$} \\
\cline { 2 - 11 } & $\begin{array}{c}\text { Fase } \\
\text { fria }\end{array}$ & $\begin{array}{c}\text { Fase } \\
\text { quente }\end{array}$ & Total & $\begin{array}{c}\text { Fase } \\
\text { fria }\end{array}$ & $\begin{array}{c}\text { Fase } \\
\text { quente }\end{array}$ & Total & $\begin{array}{c}\text { Fase } \\
\text { fria }\end{array}$ & $\begin{array}{c}\text { Fase } \\
\text { quente }\end{array}$ & Total \\
\hline AF18/13 & 4,27 & 3,52 & 3,77 & 23,4 & 28,4 & 26,7 & 1,96 & 3,90 & 5,86 \\
\hline AF19/13 & 4,29 & 3,62 & 3,85 & 23,3 & 27,6 & 26,2 & 1,97 & 3,90 & 5,87 \\
\hline AF24/13 & 4,29 & 3,47 & 3,74 & 23,3 & 28,9 & 27,0 & 1,93 & 3,90 & 5,83 \\
\hline MÉDIA & 4,28 & 3,54 & 3,79 & 23,3 & 28,3 & 26,6 & 1,95 & 3,90 & 5,85 \\
\hline
\end{tabular}

Combustível Etanol - WMTC

\begin{tabular}{|c|c|c|c|c|c|c|c|c|c|c|c|c|}
\hline \multirow[b]{2}{*}{ TESTES } & \multicolumn{3}{|c|}{$\mathrm{CO}(\mathrm{g} / \mathrm{km})$} & \multicolumn{3}{|c|}{$\mathrm{HC}(\mathrm{g} / \mathrm{km})$} & \multicolumn{3}{|c|}{ NO $(\mathrm{g} / \mathrm{km})$} & \multicolumn{3}{|c|}{$\mathrm{CO} 2(\mathrm{~g} / \mathrm{km})$} \\
\hline & $\begin{array}{c}\text { Fase } \\
\text { fria }\end{array}$ & $\begin{array}{c}\text { Fase } \\
\text { quente }\end{array}$ & Total & $\begin{array}{c}\text { Fase } \\
\text { fria }\end{array}$ & $\begin{array}{c}\text { Fase } \\
\text { quente }\end{array}$ & Total & $\begin{array}{c}\text { Fase } \\
\text { fria }\end{array}$ & $\begin{array}{c}\text { Fase } \\
\text { quente }\end{array}$ & Total & $\begin{array}{c}\text { Fase } \\
\text { fria }\end{array}$ & $\begin{array}{c}\text { Fase } \\
\text { quente }\end{array}$ & Total \\
\hline AF20/13 & 2,21 & 0,20 & 0,84 & 0,215 & 0,027 & 0,086 & 0,035 & 0,179 & 0,134 & 46,3 & 41,3 & 42,9 \\
\hline AF21/13 & 2,20 & 0,41 & 0,97 & 0,241 & 0,032 & 0,098 & 0,033 & 0,172 & 0,129 & 47,0 & 42,1 & 43,6 \\
\hline AF26/13 & 2,19 & 0,29 & 0,88 & 0,233 & 0,027 & 0,091 & 0,032 & 0,146 & 0,111 & 43,8 & 39,3 & 40,7 \\
\hline AF27/13 & 2,37 & 0,34 & 0,97 & 0,238 & 0,030 & 0,095 & 0,030 & 0,152 & 0,114 & 45,1 & 40,4 & 41,9 \\
\hline MÉDIA & 2,24 & 0,31 & 0,91 & 0,232 & 0,029 & 0,092 & 0,033 & 0,162 & 0,122 & 45,6 & 40,8 & 42,3 \\
\hline
\end{tabular}

\begin{tabular}{|c|c|c|c|c|c|c|c|c|c|c|c|c|}
\hline \multirow{2}{*}{ TESTES } & \multicolumn{3}{|c|}{ Formaldeido $(\mathrm{g} / \mathrm{km})$} & \multicolumn{3}{|c|}{ Acetaldeído $(\mathrm{g} / \mathrm{km})$} & \multicolumn{3}{c|}{ Aldeídos Totais $(\mathrm{g} / \mathrm{km})$} & \multicolumn{3}{c|}{ ANQ (g/km) } \\
\cline { 2 - 14 } & $\begin{array}{c}\text { Fase } \\
\text { fria }\end{array}$ & $\begin{array}{c}\text { Fase } \\
\text { quente }\end{array}$ & Total & $\begin{array}{c}\text { Fase } \\
\text { fria }\end{array}$ & $\begin{array}{c}\text { Fase } \\
\text { quente }\end{array}$ & Total & $\begin{array}{c}\text { Fase } \\
\text { fria }\end{array}$ & $\begin{array}{c}\text { Fase } \\
\text { quente }\end{array}$ & Total & $\begin{array}{c}\text { Fase } \\
\text { fria }\end{array}$ & $\begin{array}{c}\text { Fase } \\
\text { quente }\end{array}$ & Total \\
\hline AF20/13 & 0,006 & 0,003 & 0,004 & 0,066 & 0,010 & 0,027 & 0,0716 & 0,0126 & 0,0311 & 1,023 & 0,000 & 0,321 \\
\hline AF21/13 & 0,006 & 0,003 & 0,004 & 0,070 & 0,009 & 0,028 & 0,0758 & 0,0120 & 0,0317 & 0,944 & 0,000 & 0,296 \\
\hline AF26/13 & 0,007 & 0,003 & 0,004 & 0,057 & 0,009 & 0,024 & 0,0641 & 0,0121 & 0,0283 & 1,125 & 0,000 & 0,350 \\
\hline MÉDIA & 0,006 & 0,003 & 0,004 & 0,064 & 0,009 & 0,027 & 0,0705 & 0,0123 & 0,0304 & 1,031 & 0,000 & 0,322 \\
\hline
\end{tabular}

\begin{tabular}{|c|c|c|c|c|c|c|c|c|c|}
\hline \multirow{2}{*}{ TESTES } & \multicolumn{3}{|c|}{ Consumo $(\mathbf{l} / 100 \mathrm{~km})$} & \multicolumn{3}{c|}{ Autonomia $(\mathrm{km} / \mathrm{l})$} & \multicolumn{2}{c|}{ Distância pecorrida $(\mathrm{km})$} \\
\cline { 2 - 11 } & $\begin{array}{c}\text { Fase } \\
\text { fria }\end{array}$ & $\begin{array}{c}\text { Fase } \\
\text { quente }\end{array}$ & Total & $\begin{array}{c}\text { Fase } \\
\text { fria }\end{array}$ & $\begin{array}{c}\text { Fase } \\
\text { quente }\end{array}$ & Total & $\begin{array}{c}\text { Fase } \\
\text { fria }\end{array}$ & $\begin{array}{c}\text { Fase } \\
\text { quente }\end{array}$ & Total \\
\hline AF20/13 & 3,74 & 3,09 & 3,30 & 26,7 & 32,3 & 30,6 & 3,80 & 8,31 & 12,11 \\
\hline AF21/13 & 3,79 & 3,18 & 3,37 & 26,4 & 31,5 & 29,9 & 3,79 & 8,31 & 12,10 \\
\hline AF26/13 & 3,56 & 2,95 & 3,14 & 28,1 & 33,9 & 32,1 & 3,74 & 8,27 & 12,02 \\
\hline AF27/13 & 3,68 & 3,04 & 3,24 & 27,2 & 32,9 & 31,1 & 3,73 & 8,26 & 12,00 \\
\hline MÉDIA & 3,69 & 3,07 & 3,26 & 27,1 & 32,6 & 30,9 & 3,77 & 8,29 & 12,06 \\
\hline
\end{tabular}


B) Combustível gasolina - E22

\begin{tabular}{|c|c|c|c|c|c|c|c|c|c|c|c|c|}
\hline \multirow[b]{2}{*}{ TESTES } & \multicolumn{3}{|c|}{$\mathrm{CO}(\mathrm{g} / \mathrm{km})$} & \multicolumn{3}{|c|}{$\mathrm{HC}(\mathrm{g} / \mathrm{km})$} & \multicolumn{3}{|c|}{ NO $(\mathrm{g} / \mathrm{km})$} & \multicolumn{3}{|c|}{$\mathrm{CO} 2(\mathrm{~g} / \mathrm{km})$} \\
\hline & $\begin{array}{l}\text { Fase } \\
\text { fria }\end{array}$ & $\begin{array}{c}\text { Fase } \\
\text { quente }\end{array}$ & Total & $\begin{array}{l}\text { Fase } \\
\text { fria }\end{array}$ & $\begin{array}{c}\text { Fase } \\
\text { quente }\end{array}$ & Total & $\begin{array}{l}\text { Fase } \\
\text { fria }\end{array}$ & $\begin{array}{c}\text { Fase } \\
\text { quente }\end{array}$ & Total & $\begin{array}{c}\text { Fase } \\
\text { fria }\end{array}$ & $\begin{array}{c}\text { Fase } \\
\text { quente }\end{array}$ & Total \\
\hline AF11/13 & 2,34 & 0,31 & 0,99 & 0,339 & 0,055 & 0,150 & 0,069 & 0,026 & 0,040 & 53,4 & 50,6 & 51,5 \\
\hline AF12/13 & 2,16 & 0,27 & 0,90 & 0,334 & 0,056 & 0,149 & 0,065 & 0,028 & 0,040 & 54,3 & 49,1 & 50,9 \\
\hline AF13/13 & 2,61 & 0,29 & 1,06 & 0,393 & 0,062 & 0,173 & 0,048 & 0,027 & 0,034 & 53,5 & 50,3 & 51,4 \\
\hline MÉDIA & 2,37 & 0,29 & 0,99 & 0,36 & 0,06 & 0,16 & 0,06 & 0,03 & 0,04 & 53,71 & 50,03 & 51,26 \\
\hline
\end{tabular}

\begin{tabular}{|c|c|c|c|c|c|c|c|c|c|}
\hline \multirow{2}{*}{ TESTES } & \multicolumn{2}{|c|}{ Formaldeido $(\mathbf{g} / \mathbf{k m})$} & \multicolumn{2}{c|}{ Acetaldeído $(\mathbf{g} / \mathbf{k m})$} & \multicolumn{2}{|c|}{ Aldeídos Totais $(\mathrm{g} / \mathrm{km})$} \\
\cline { 2 - 10 } & $\begin{array}{c}\text { Fase } \\
\text { fria }\end{array}$ & $\begin{array}{c}\text { Fase } \\
\text { quente }\end{array}$ & Total & $\begin{array}{c}\text { Fase } \\
\text { fria }\end{array}$ & $\begin{array}{c}\text { Fase } \\
\text { quente }\end{array}$ & Total & $\begin{array}{c}\text { Fase } \\
\text { fria }\end{array}$ & $\begin{array}{c}\text { Fase } \\
\text { quente }\end{array}$ & Total \\
\hline $\mathrm{AF11/13}$ & 0,002 & 0,000 & 0,001 & 0 & 0 & 0 & 0,0018 & 0,0004 & 0,0009 \\
\hline $\mathrm{AF} 12 / 13$ & 0,002 & 0,000 & 0,001 & 0 & 0 & 0 & 0,0018 & 0,0004 & 0,0009 \\
\hline $\mathrm{AF} 13 / 13$ & 0,002 & 0,000 & 0,001 & 0 & 0 & 0 & 0,0017 & 0,0004 & 0,0009 \\
\hline $\mathrm{MÉDIA}$ & 0,002 & 0,000 & 0,001 & 0 & 0 & 0 & 0,0018 & 0,0004 & 0,0009 \\
\hline
\end{tabular}

\begin{tabular}{|c|c|c|c|c|c|c|c|c|c|}
\hline \multirow{2}{*}{ TESTES } & \multicolumn{3}{|c|}{ Consumo $(\mathrm{I} / 100 \mathrm{~km})$} & \multicolumn{2}{c|}{ Autonomia (km/l) } & \multicolumn{2}{c|}{ Distância pecorrida $(\mathrm{km})$} \\
\cline { 2 - 11 } & $\begin{array}{c}\text { Fase } \\
\text { fria }\end{array}$ & $\begin{array}{c}\text { Fase } \\
\text { quente }\end{array}$ & Total & $\begin{array}{c}\text { Fase } \\
\text { fria }\end{array}$ & $\begin{array}{c}\text { Fase } \\
\text { quente }\end{array}$ & Total & $\begin{array}{c}\text { Fase } \\
\text { fria }\end{array}$ & $\begin{array}{c}\text { Fase } \\
\text { quente }\end{array}$ & Total \\
\hline AF11/13 & 2,66 & 2,35 & 2,45 & 37,6 & 42,6 & 40,9 & 1,94 & 3,89 & 5,83 \\
\hline AF12/13 & 2,69 & 2,28 & 2,42 & 37,2 & 43,9 & 41,6 & 1,94 & 3,87 & 5,81 \\
\hline AF13/13 & 2,70 & 2,34 & 2,46 & 37,1 & 42,8 & 40,9 & 1,93 & 3,84 & 5,78 \\
\hline MÉDIA & 2,68 & 2,32 & 2,44 & 37,3 & 43,1 & 41,1 & 1,94 & 3,87 & 5,81 \\
\hline
\end{tabular}

Combustível Gasolina- WMTC

\begin{tabular}{|c|c|c|c|c|c|c|c|c|c|c|c|c|}
\hline \multirow[b]{2}{*}{ TESTES } & \multicolumn{3}{|c|}{$\mathrm{CO}(\mathrm{g} / \mathrm{km})$} & \multicolumn{3}{|c|}{$\mathrm{HC}(\mathrm{g} / \mathrm{km})$} & \multicolumn{3}{|c|}{ NO $(\mathrm{g} / \mathrm{km})$} & \multicolumn{3}{|c|}{$\mathrm{CO2}(\mathrm{g} / \mathrm{km})$} \\
\hline & $\begin{array}{c}\text { Fase } \\
\text { fria }\end{array}$ & $\begin{array}{c}\text { Fase } \\
\text { quente }\end{array}$ & Total & $\begin{array}{c}\text { Fase } \\
\text { fria }\end{array}$ & $\begin{array}{c}\text { Fase } \\
\text { quente }\end{array}$ & Total & $\begin{array}{c}\text { Fase } \\
\text { fria }\end{array}$ & $\begin{array}{c}\text { Fase } \\
\text { quente }\end{array}$ & Total & $\begin{array}{c}\text { Fase } \\
\text { fria }\end{array}$ & \begin{tabular}{|c|}
$\begin{array}{c}\text { Fase } \\
\text { quente }\end{array}$ \\
\end{tabular} & Total \\
\hline AF07/13 & 1,34 & 0,39 & 0,69 & 0,229 & 0,060 & 0,113 & 0,071 & 0,171 & 0,140 & 55,3 & 42,7 & 46,7 \\
\hline AF08/13 & 1,58 & 0,33 & 0,71 & 0,252 & 0,058 & 0,118 & 0,073 & 0,164 & 0,136 & 47,2 & 44,8 & 45,6 \\
\hline AF09/13 & 1,51 & 0,55 & 0,85 & 0,254 & 0,060 & 0,121 & 0,054 & 0,153 & 0,122 & 49,1 & 43,5 & 45,2 \\
\hline MÉDIA & 1,47 & 0,42 & 0,75 & 0,245 & 0,060 & 0,117 & 0,066 & 0,163 & 0,133 & 50,6 & 43,7 & 45,8 \\
\hline
\end{tabular}

\begin{tabular}{|c|c|c|c|c|c|c|c|c|c|}
\hline \multirow{2}{*}{ TESTES } & \multicolumn{3}{|c|}{ Formaldeido $(\mathrm{g} / \mathrm{km})$} & \multicolumn{3}{c|}{ Acetaldeído $(\mathrm{g} / \mathrm{km})$} & \multicolumn{3}{|c|}{ Aldeídos Totais $(\mathrm{g} / \mathrm{km})$} \\
\cline { 2 - 10 } & $\begin{array}{c}\text { Fase } \\
\text { fria }\end{array}$ & $\begin{array}{c}\text { Fase } \\
\text { quente }\end{array}$ & Total & $\begin{array}{c}\text { Fase } \\
\text { fria }\end{array}$ & $\begin{array}{c}\text { Fase } \\
\text { quente }\end{array}$ & Total & $\begin{array}{c}\text { Fase } \\
\text { fria }\end{array}$ & $\begin{array}{c}\text { Fase } \\
\text { quente }\end{array}$ & Total \\
\hline AF07/13 & 0,005 & 0,002 & 0,003 & 0,007 & 0,002 & 0,003 & 0,0119 & 0,0034 & 0,0060 \\
\hline AF08/13 & 0,004 & 0,002 & 0,003 & 0,006 & 0,001 & 0,003 & 0,0105 & 0,0027 & 0,0052 \\
\hline AF09/13 & 0,004 & 0,003 & 0,003 & 0,006 & 0,000 & 0,002 & 0,0106 & 0,0030 & 0,0053 \\
\hline MÉDIA & 0,004 & 0,002 & 0,003 & 0,007 & 0,001 & 0,003 & 0,0110 & 0,0030 & 0,0055 \\
\hline
\end{tabular}

\begin{tabular}{|c|c|c|c|c|c|c|c|c|c|}
\hline \multirow{2}{*}{ TESTES } & \multicolumn{3}{|c|}{ Consumo $(\mathrm{l} / 100 \mathrm{~km})$} & \multicolumn{3}{c|}{ Autonomia $(\mathrm{km} / \mathrm{l})$} & \multicolumn{2}{c|}{ Distância pecorrida $(\mathrm{km})$} \\
\cline { 2 - 11 } & $\begin{array}{c}\text { Fase } \\
\text { fria }\end{array}$ & $\begin{array}{c}\text { Fase } \\
\text { quente }\end{array}$ & Total & $\begin{array}{c}\text { Fase } \\
\text { fria }\end{array}$ & $\begin{array}{c}\text { Fase } \\
\text { quente }\end{array}$ & Total & $\begin{array}{c}\text { Fase } \\
\text { fria }\end{array}$ & $\begin{array}{c}\text { Fase } \\
\text { quente }\end{array}$ & Total \\
\hline AF07/13 & 2,66 & 1,99 & 2,20 & 37,5 & 50,2 & 46,2 & 3,77 & 8,26 & 12,03 \\
\hline AF08/13 & 2,31 & 2,08 & 2,16 & 43,2 & 48,0 & 46,5 & 3,71 & 8,25 & 11,96 \\
\hline AF09/13 & 2,40 & 2,04 & 2,15 & 41,7 & 49,0 & 46,7 & 3,73 & 8,26 & 11,98 \\
\hline MÉDIA & 2,46 & 2,04 & 2,17 & 40,8 & 49,0 & 46,5 & 3,74 & 8,26 & 11,99 \\
\hline
\end{tabular}

